\title{
DE AFECTOS Y PRECEPTOS: ESPINOSA Y LO POLÍTICO
}

\author{
Pedro LOMBA
}

Abstract: Starting from the apparent paradox presented, on the one hand, by denouncing the sensibilities of hope and fear as negative and enslaving, and, on the other, determining their political use as absolutely necessary for the establishing of rationality in public life, this article hopes to investigate and so clarify the relationship between sensibility and rationality in Spinoza's philosophy of inmanence. This relationship, and above all a certain equilibrium between the two terms, is essential in order to define politics such as Spinoza conceived it.

De afectos y preceptos: Espinosa y lo político

En el capítulo 16 del Tratado teológico-político ${ }^{1}$ Espinosa habla del pacto que instaura la sociedad civil como de un medio en virtud del cual se hace posible dirigir las acciones de los integrantes de dicha sociedad "por el solo dictamen de la razón". Sin embargo, la validez y sobre todo la firmeza y mantenimiento de dicho pacto sólo encuentran sus condiciones de posibilidad en la utilidad y en los afectos de la esperanza y el miedo... Pero, ¿no resulta paradójico fundar las condiciones de validez y firmeza del medio que inscribe la racionalidad en la vida social en unos afectos que en la Ética han sido denunciados como pasivos y esclavizantes? Y si tal paradoja es tan sólo aparente, ¿qué rela-

1 A partir de ahora, TTP. La edición uilizada es la de Alianza editorial, Madrid, 1986 (traducción de Atilano Domínguez). En cuanto a la Ética (Eth.), la edición empleada es la de Vidal Peña para Editora Nacional, Madrid, 1975. 
ciones mantendrá entonces la razón con la afectividad en una filosofía de la inmanencia como es la espinosista? Con las siguientes consideraciones intentaré dar una respuesta a estos interrogantes tratando de mostrar cómo la ley positiva, aunque desemejante de la racionalidad en sentido estricto, juega sin embargo un papel fundamental en la introducción de esa racionalidad en el mundo social y político de los hombres.

Desde el momento en que el campo ontológico de lo real es pensado como campo de inmanencia toda posición de exterioridad que pretenda dar cuenta del tránsito de la inadecuación a la adecuación ha de ser rechazada en favor de una cierta continuidad entre afectividad y entendimiento. El medio que nos separa del conocimiento verdadero se presenta como necesario, como medio en el cual están ya, ahora, cuando la perspectiva abierta por el conocimiento adecuado no ha sido aún alcanzada, los elementos que nos permiten el abandono del horizonte propio de este medio de la inadecuación. No va a ser ya posible pensar lo inadecuado como mero punto de partida hacia la apropiación de algo que es adecuado pero que se encuentra en un ámbito trascendente $y$ fundante respecto de aquello de lo que debemos partir. El conocimiento y sobre todo su operatividad van a mantener relaciones esenciales con lo que no constituye ello mismo ni conocimiento ni verdad en sentido estricto. Y ello porque la naturalización de la Sustancia, su inmanentización, implicará la aceptación axiomática de la racionalidad propia de todas sus determinaciones (expresen lo que expresen: adecuación o inadecuación) en tanto que determinaciones propias de esa misma Sustancia. La Sustancia se determina a sí misma y desde sí misma. Es nada más — nada menos- que pura autoconstitución, y, por ello, afirmación y afirmatividad de todos y cada uno de los momentos en que se autoconstituye.

En estrecha conexión con esto, se hace necesario pensar aquello que transita el medio que no constituye conocimiento en sentido estricto como distinto de una instancia que en virtud de su originaria pertenencia a un ámbito trascendente en el que se hallan contenidos los elementos de la verdad, nos posibilita su apropiación. El engarce entre los extremos del conocimiento verdadero y la existencia material será pensado mediante el concepto de fuerza, de potencia. La conciencia no será derivable sino de sus condiciones materiales de emergencia. El momento de la Sustancia única e infinita que es todo modo finito -pongamos un caso: el hombre- no podrá ser ya definido en su esencia como sustancia, sino como deseo. Es un deseo, una estructura inderivable expresada como afectividad, aquello que recorre el espacio intermedio entre la 
inadecuación y la adecuación abarcando a ambos. Es decir, el deseo define y por tanto acompaña al hombre tanto cuando alcanza el conocimiento verdadero (cuando actúa) como cuando se encuentra en el espacio de la inadecuación (cuando padece). Pero al margen de que la afectividad se encuentre presente en ambos momentos, en el de la adecuación y en el de la inadecuación, es de éste último de donde hay que partir. Es necesario partir de la estructura del modo finito, de aquello que no es sino recorte, configuración limitada de lo indefinido, y recorte que se expresa y conoce en principio como negación, como limitación.

Pues bien, la existencia de la individualidad que es el modo finito transcurre en el marco de un horizonte plural de individualidades, de potencias, en un campo plural de fuerzas. Es este campo lo que determina la acción y la emergencia en la existencia de los individuos que en él aparecen -y lo hacen en tanto que resultantes de los conflictos o composiciones de las fuerzas preexistentes. Esto es, toda esencia se halla precedida y constituida por la realidad y operatividad de un campo material de potencias que condiciona y posibilita la emergencia de toda cosa, siendo dicha esencia actualizada o disuelta según lo sea la cosa de la cual es esencia. Por tanto, la esencia de toda cosa singular queda pertinazmente adherida a su carácter de singularidad ${ }^{2}$. Y si el modo finito de que estamos tratando es el hombre, esta pertinaz adherencia podrá reconocerse como una copertenencia constitutiva: la del alma con respecto al cuerpo y viceversa.

Es esta especial copertenencia lo que determina el anclaje del hombre en la existencia, y lo que determina el que se encuentre en un principio, y desde el principio, en el elemento de la inadecuación. Si cuerpo y alma se configuran recíprocamente en virtud de su hallarse inmersos en un horizonte plural de cuerpos y almas cuya interacción configura y determina a la acción a todo modo finito, habrá de ser una cierta capacidad de afectar y de ser afectado lo que defina al hombre. El contacto y conflicto, la dinamicidad constitutiva del horizonte modal implica una consideración de la afectividad como resultante de esa misma dinamicidad que no sólo permite al alma conocer su cuerpo y conocerse a sí misma, sino que posibilita al modo finito constituido como composición de alma y cuerpo relacionarse en el espacio de la negatividad en

2 Cf. Eth. II, 37: «Aquello que es común a todas las cosas, y que está igualmente en la parte y en el todo, no constituye la esencia de ninguna cosa singularm. 
que se halla inmerso, es decir, conocer además los otros modos finitos. Pero esta triple relación cognoscitiva ejercida a partir de la traducción de este primer tipo de afectividad en ideas es siempre inadecuada.

Ello es así porque este elemento del contacto y el conflicto, de la oposición y confrontación entre los modos, es, en palabras de Espinosa, el elemento de la determinación exterior, de la causalidad transitiva. Lo singular como momento de la Sustancia única, como determinación finita de lo indefinido, no puede ser determinado en el ámbito de su existencia de la manera como se determina la Sustancia. El modo finito existe en un ámbito cuya determinabilidad a la acción y al existir viene dada en función de una causalidad de tipo transitivo, ámbito éste al que Espinosa denomina uorden común de la naturaleza" ${ }^{3}$. El modo mismo no puede percibirse ni concebirse, en principio, como momento de una Sustancia que se autoconstituye y autoregula en virtud de una causalidad de tipo inmanente. Y sin embargo, la totalidad de ese ámbito de la pluralidad modal no es otra cosa que la Sustancia misma. Se hace necesario encontrar una salida a este espacio de la inadecuación, de la ficción.

Espinosa insiste en que la inadecuación y el error no son sino figuras que adopta la negatividad implicada en el modo finito, es decir, en que el error y la ficción no están en las ideas (inadecuadas) mismas, sino en la relación mantenida entre esas ideas y un alma que es siempre idea de un cuerpo separado de, pero en relación necesaria con, otros cuerpos. El que tanto nuestra existencia como nuestra actividad se hallen en dependencia directa de otros modos finitos que a su vez tampoco son sino partes componentes de un horizonte plural de potencias en conflicto, es lo que determina la causalidad propia de este ámbito como causalidad transitiva, inadecuada. Y la imposibilidad de comprender cada una de esas partes desde sí misma y al margen de su necesaria relación con las demás, con todas las demás, es lo que determina la inadecuación de nuestro conocimiento en este ámbito.

Pues bien, es este horizonte de la determinación exterior, este horizonte de partes extra partes, el que determina la forma de la afectividad en este primer momento como afectividad pasiva, el que configura el espacio de la pasividad. Y lo hace en la medida en que la imaginación resultante de la confrontación y

3 Cf. Eth. II 29, cor: “(...) el alma humana, cuantas veces percibe las cosas según el orden común de la naturaleza, no tiene un conocimiento adecuado ni de sí misma, ni de su cuerpo, ni de los cuerpos exteriores, sino tan sólo un conocimiento confuso y mutilado». 
el conflicto entre los modos insiste en el aislamiento y separación de aquello cuya composición, cuya resolución en una totalidad, conforma un ámbito en el que la causalidad operante es necesariamente adecuada. La imaginación es inadecuación que constituye pasividad porque enlaza al menos dos singularidades separándolas. A lo que conspira la imaginación, el conocimiento inadecuado, es a la consideración de lo que es parte como todo -a la consideración, por ejemplo, del ser del hombre como sustantivo. Y ello, en virtud de que es a partir de una oposición como formamos una idea separada de los modos en este primer momento, idea que en función de esa separación es siempre inadecuada 4 .

Pero si de lo que se trata es de alcanzar una perspectiva en la que haya sido abandonada la inadecuación habrá que comenzar constatando aquello que diferencia al entendimiento de la imaginación. En primer lugar, si esa imaginación que se constituía siempre como afectividad pasiva insistía en la consideración de la singularidad como singularidad percibiéndola como totalidad sustantiva, $y$, como dice Espinosa, "Un afecto de un individuo difiere del afecto de otro, tanto cuanto difiere la esencia de uno de la esencia de otron ${ }^{5}$, el entendimiento, por el contrario, se presentará como el mismo en todos los hombres ${ }^{6}$. Con lo cual, el entendimiento tendrá que ver no ya con aquello en que difieren las singularidades y que insiste en la consideración de lo singular en cuanto tal, sino que se fundará en una cierta comprensión de aquello que explica lo que es común a todas las cosas pero no explica la esencia de ninguna cosa singular. Se fundará en lo que Espinosa denomina "nociones comunes». Ahora bien, si la imaginación es subsidiaria de un cierto tipo de relaciones entre los modos, relaciones éstas que determinan el ser pasivo de la afectividad, pero la afectividad es algo presente también en el momento de la adecuación, será condición necesaria entonces la concurrencia de un tipo diferente de relaciones entre los modos para llegar a la consideración de lo común a todas las cosas, para llegar a apropiarnos de un conocimiento adecuado, racional.

En efecto, si imaginación e inadecuación se coimplican no pudiendo ir ambas más allá de la representación de lo singular como singularidad, y esto es posibilitado por unas relaciones de oposición y confrontación, será un tipo dis-

4 Cf. Carta XXXII a Enrique Oldenburgh.

5 Eth. III, 57.

6 Cf. Eth. II, 18 sch. 
tinto de relaciones lo que condicione el abandono de esta perspectiva de la inadecuación, lo que condicione la consideración de aquello que, sin explicar la esencia de ninguna cosa singular, explica lo que es común a todas ellas. Estas relaciones permitirán considerar la acción de los modos en tanto que exprese actividad y no ya pasividad. $\mathrm{Si}$ "el orden de las acciones y pasiones de nuestro cuerpo se corresponde por naturaleza con el orden de las acciones y pasiones del alma» " las relaciones en que entren los cuerpos cuando el alma actúe serán contradistintas de las relaciones que mantienen cuando ésta padece. A partir de este tipo distinto de relaciones se podrá escapar de la pasividad en la que estaba anclada la existencia del modo finito. A partir de ellas se podrá ejercer el entendimiento, podremos ser activos.

Efectivamente, y esto lo ha explicado magistralmente Deleuze, si el alma es idea del cuerpo, si el alma no es concebida como algo cuya naturaleza pertenece a, o se vincula esencialmente con, una trascendencia de la que ha sido separada, será entonces nuestra corporalidad constitutiva lo que nos conduzca hacia la adecuación de nuestras ideas, lo que nos lleve a esas nociones comunes fundamento de la actividad del entendimiento. Y si la manera de nuestro originario estar en el mundo consistía en una capacidad de afectar y de ser afectado, la diferencia entre nuestra actividad y pasividad cognoscitivas habrá de pasar necesariamente por una diferenciación entre afecciones que sean también activas y pasivas. Pues bien, la identidad de esencia entre idea e ideado remitirá a cierto tipo de relaciones a partir de las cuales lleguemos a las nociones comunes. Estas relaciones, al contrario que aquellas que determinaban el conocimiento imaginativo y la pasividad, expresarán una conveniencia con lo que nos afecta, serán aquellas en que nuestro cuerpo se compone con el cuerpo que le afecta, siendo la afección derivada de esta composición una afección dichosa, alegre, la cual es indicativa de actividad, del paso a una mayor perfección, pues aumenta nuestra potencia de acción. Las nociones comunes encuentran en la afectividad, en una afectividad formalmente compartida con lo que no constituye entendimiento ni adecuación, las condiciones mismas de su formación. Es decir, la alegría surgida del hecho de que nuestro cuerpo se compone con otros cuerpos, aunque sigue consistiendo en una afectividad de suyo pasiva en virtud de que esa composición es siempre y necesariamente limitada (afectividad alegre pasiva), conviene sin embargo con nuestra razón,

7 Eth, II, 2 sch. 
pues no sólo es condición de posibilidad de la formación de nociones comunes, sino que es de un tipo tendencialmente idéntico a la afectividad propia del entendimiento (afectividad alegre activa). Pues bien, es en virtud de este espacio de intersección entre la afectividad pasiva alegre y la afectividad activa propia del entendimiento como se hace posible el ejercicio de la racionalidad sobre lo que no constituye ello mismo racionalidad en sentido estricto. El requisito primero para salir de la inadecuación se cifrará en una selección de los afectos pasionales. Y si esto es así, será en esta selectividad en donde se constituya el ejercicio práctico de la racionalidad.

En efecto, si la afectividad enlaza genéticamente los extremos de lo adecuado y de lo inadecuado permaneciendo presente en ambos, será precisamente en el elemento de esa misma afectividad donde se despliegue una interacción entre ambos extremos que pretenda ser legislativa. Será a partir de los afectos generados desde la actividad racional desde donde se haga posible la moderación o represión de lo pasional. La acción de lo racional sobre lo pasional no será ejercida a partir de la racionalidad intrínseca de lo que actúa, a partir de lo que genera afectos activos (el entendimiento en cuanto tal), sino en virtud de su ser afectivo, de su implicar una afectividad de tipo distinto de aquella en la que consiste lo que pretende legislar. La comunidad afectiva formal entre las pasiones (afectividad pasiva) y el entendimiento fundado a partir de ideas adecuadas o nociones comunes (afectividad activa) se constituye como espacio articulador del ejercicio de la racionalidad sobre las pasiones.

Sin embargo, este espacio común de la afectividad debe ser transitado en la mayoría de las ocasiones por representaciones de tipo inadecuado. La racionalidad o actividad que podemos llegar a ser capaces de ejercer sólo puede legislar aquello a lo que se enfrenta mediante imágenes. Si los afectos sólo pueden ser reprimidos mediante afectos, la afectividad generada por el hecho de que en determinadas ocasiones seamos activos ha de manejar, para ser efectiva al gestionar el mundo de los modos, imágenes que se opongan a aquellas imágenes que constituyen los afectos que la razón exige moderar o reprimir. Es decir, de lo que se trata es de gestionar desde la actividad, desde la adecuación, una pasividad que sea solidaria de, y concurrente con, las exigencias que la propia racionalidad reivindica para poder ser pregnante en el mundo de los modos.

Por paradójica que resulte esta formulación, esto no puede dejar de ser así desde el momento en que constatamos la especial «bidireccionalidad» que atraviesa ese espacio articulador de la legislación o del ejercicio de la racionalidad 
sobre las pasiones. Constituye un espacio en el que se puede recorrer un doble camino: el deseo que nace del hecho de que conocemos verdaderamente algo puede ser capaz de reprimir el deseo y la pasión nacidos de la inadecuación, de la imaginación. Pero también puede suceder, y de hecho sucede casi siempre y en casi todos los hombres, lo contrario: las pasiones pueden reprimir los deseos nacidos de la racionalidad.

La racionalidad en sentido estricto, en sentido esencialista, se sitúa en un ámbito indiferente a las determinaciones temporales (pasado, presente y futuro). El conocimiento verdadero no hace referencia específica a los momentos del tiempo. Y, al no hacerla, su afectividad propia podrá vincularse en un mismo grado a cualquiera de esos momentos. Dice Espinosa: "En la medida en que el alma concibe las cosas según el dictamen de la razón, es afectada igualmente por la idea de una cosa futura que por la de una pretérita o presente» ${ }^{8}$. Es decir, la afectividad generada en virtud de que en determinadas ocasiones somos capaces de entender, aunque en tanto que afectividad se ligue esencialmente a la temporalidad, no se halla determinada por la distinción temporal. Pero si de lo que se trata es de que legisle aquello que de ninguna manera puede dejar de estar inscrito en un horizonte espacio temporal concreto, y lo hace desde una afectividad que posee formalmente en común con lo que trata de legislar, el deseo y la afectividad propios de la racionalidad podrán ser reprimidos por la afectividad propia de lo intrínsecamente temporal, de la inadecuación. De ahí que se haga necesaria para la moderación de lo pasional la concurrencia, pero ahora gestionada desde la comprensión racional, de una afectividad pasiva de contenido contrario. Lo que va a ser posible es un uso ético-político de los afectos ya que su supresión resulta imposible. De lo que se tratará será de que el ejercicio de la razón sobre las pasiones recurra a su afectividad específica modificándolos o dotándolos de la forma necesaria para que sean ellos mismos capaces de impulsar conductas racionales o, en el caso de la política, de mantener en la existencia aquello que constituye una exigencia de la razón: por ejemplo, la seguridad y la unidad del Estado.

Pues bien, la ley positiva se presentará como medio para la consecución de determinados fines de la razón, pero como medio o instrumento propio del elemento de la afectividad racional, o sea, como instrumento que debe reves-

8 Eth. IV, 62. 
tir la forma de la inadecuación. La ley positiva tendrá la forma de la representación inadecuada, será una ficción perteneciente por tanto al ámbito de la inadecuación, al insistir en el mantenimiento del juego de oposiciones propio del horizonte de la negatividad, pues es este horizonte el único en que puede ser operativa. Ello es así desde el momento en que la unidad de los componentes de ese individuo compuesto al que llamamos Estado, unidad que es requisito indispensable para su seguridad, precisa de un vínculo que tan sólo es capaz de ser efectivo bajo la forma de la afectividad pasiva. Dicho de otra manera: para que la racionalidad o para que lo exigido por la razón pueda ser cumplido se hace necesaria la concurrencia de lo que no es en sí mismo racional en el sentido de ajeno a las determinaciones temporales. Y el cumplimiento de esta exigencia sólo podrá ser llevado a cabo en el interior de un juego de limitaciones y confrontaciones recíprocas arbitrado a través de una legalidad positiva que no puede sino establecer y fomentar determinados afectos pasionales pasivos en virtud de la naturaleza temporal, modal, inscrita esencialmente en el horizonte de la inadecuación, del hombre. Dice Espinosa en el capítulo 5 del TTP: «(...) si los hombres estuvieran constituidos por naturaleza de tal forma que no desearan nada fuera de lo que la verdadera razón les indica, la sociedad no necesitaría ley alguna, sino que sería absolutamente suficiente enseñar a los hombres doctrinas verdaderas para que hicieran espontáneamente, $y$ con ánimo sincero y libre, lo que es verdaderamente útil. Pero la verdad es que la naturaleza humana está constituida de forma muy distinta (...). De donde resulta que ninguna sociedad puede subsistir sin autoridad, sin fuerza $y$, por tanto, sin leyes que moderen y controlen el ansia de placer y los impulsos desenfrenados» ${ }^{9}$. La ley positiva queda caracterizada como ficción dependiente del arbitrio humano que genera, gestionando la afectividad, un espacio cuya emergencia es exigida por la razón pero cuyo mantenimiento y funcionamiento sólo es posible a través de un juego de representaciones de carácter ficticio. La racionalidad política nada será al margen de este juego de representaciones. La racionalidad política nada podrá legislar si no atraviesa los cuerpos. 